FEDERAL RESERVE BANK OF SAN FRANCISCO

WORKING PAPER SERIES

\title{
Productivity Shocks in a Model with Vintage Capital and Heterogeneous Labor
}

\author{
Milton H. Marquis \\ Florida State University \\ and \\ Bharat Trehan \\ Federal Reserve Bank of San Francisco
}

January 2007

Working Paper 2007-06

http://www.frbsf.org/publications/economics/papers/2006/wp07-06bk.pdf

The views in this paper are solely the responsibility of the authors and should not be interpreted as reflecting the views of the Federal Reserve Bank of San Francisco or the Board of Governors of the Federal Reserve System. This paper was produced under the auspices for the Center for the Study of Innovation and Productivity within the Economic Research Department of the Federal Reserve Bank of San Francisco. 


\title{
PRODUCTIVITY SHOCKS IN A MODEL WITH VINTAGE CAPITAL AND HETEROGENEOUS LABOR
}

\author{
MILTON H. MARQUIS AND BHARAT TREHAN
}

\begin{abstract}
We construct a vintage capital model in which worker skills lie along a continuum and workers can be paired with different vintages (as technology evolves) under a matching rule of "best worker with the best machine". Labor reallocation in response to technology shocks has two key implications for the wage premium. First, it limits both the magnitude and duration of change in the wage premium following a (permanent) embodied technology shock, so empirically plausible shocks do not lead to the kind of increases in the wage premium observed in the U.S. during the 1980s and early 1990s (though an increase in labor force heterogeneity does). Second, positive disembodied technology shocks tend to push up the wage premium as well, and while this effect is small, it does mean that a higher premium does not provide unambiguous information about the underlying shock.

Labor reallocation also means that if embodied technology comes to play a larger role in long-run growth, investment and savings tend to fall in steady state, with little effect on output and employment, enabling the household to increase consumption without sacrificing leisure. The short run effects are more conventional: permanent shocks to disembodied technology induce a strong wealth effect that reduces savings and induces a consumption boom while permanent shocks to embodied technology induce dominant substitution effects and an expansion characterized by an investment boom.
\end{abstract}

Date: January 29, 2007.

Key words and phrases. Vintage capital, wage premium, heterogeneous labor, productivity. We thank Andrew McCallum and Jason Tjosvold for research assistance on this project. The paper has benefitted from the feedback we received at seminars at Florida State University and the Federal Reserve Bank of San Francisco. The opinions expressed in the paper are those of the authors and do not necessarily reflect the views of the Federal Reserve Bank of San Francisco or the Federal Reserve System. 


\section{INTRODUCTION}

In this paper we examine the effects of technology shocks in a model with vintage capital and a heterogeneous labor force. We focus upon two issues that have been discussed in the literature recently. One of these has to do with the relationship between the wage premium paid to high skilled workers and the growth rate of productivity. We ask, for instance, whether empirically plausible shocks to the productivity of capital can lead to increases in the wage premium that are comparable to those seen in the data. The other issue concerns the economy's response to different kinds of technology shocks, that is, we ask whether the economy reacts in the same way to embodied technology shocks (which change the productivity of the latest vintage of capital relative to earlier vintages) as it does to disembodied technology shocks (which effect all vintages equally).

Positive embodied technology shocks lead to an increase in the wage premium in our model, since the best workers are paired with the best machines. However, this effect is small and not very long lived, because of the key assumption that workers can be reallocated across vintages of capital when the technology shock hits. Thus, firms respond to an increase in the productivity of the latest vintage by reallocating labor to the latest vintage and away from the older vintages. This tends to depress the marginal product of labor (and hence the wage rate) on the newest vintage and raise the marginal product of labor on the oldest vintage, thereby mitigating the increase in the wage premium that would otherwise occur

Much previous research has argued that embodied technology shocks are behind the recent increase in the wage premium. ${ }^{1}$ In general, these

\footnotetext{
${ }^{1}$ See Katz and Murphy (1992) for an early example of the argument that increasing wage dispersion is related to skill-biased technical change. Also see Autor, Katz and Krueger (1998), Greenwood and Yorukoglu (1997) and Hornstein and Krusell (2002).
} 
models restrict the substitutability between skilled and unskilled labor. $^{2}$ For instance, Krusell, Ohanian, Rios-Rull, and Violante (KORV) (1999) argue that the economy's ever-improving technology requires an ever more highly skilled workforce, and this pushes up the wages of high-skilled workers relative to the low skilled. To us, the KORV story seems at odds with the observation that new technology ultimately permeates the entire workplace, eventually to benefit all workers. ${ }^{3}$ To take a simple example, most people in the economy today can take a high-quality photograph and operate a computer, which was not the case when those technologies were first introduced. Moreover, the skill required to perform those tasks is no more difficult to acquire than performing the comparable tasks prior to the invention of the new technology. Indeed, it is probably less difficult to master a modern-day digital camera than to draw representations of reality on a sketch pad. Utilizing new technologies may require a new and different set of skills, but these skills are not necessarily more difficult to master than the skills required to operate older technologies. ${ }^{4}$

Recent empirical evidence has not been entirely favorable to the hypothesis that the rising wage premium is related to embodied productivity growth, either. For instance, Figure 1 shows that while the wage premium rose quite sharply during the 1980s, it did not increase by

\footnotetext{
${ }^{2}$ Jovanovic(1998) is one exception.

${ }^{3}$ This argument is similar to Aghion's (2002) description of how a General Purpose Technology spreads through the workforce and the economy.

${ }^{4}$ From a modeling perspective, this distinction is not trivial. The characterization of the evolution of the distribution of human capital in KORV's model is a nonstationary process that eventually must converge to a point mass of highly skilled workers in order to prevent the wage premium from becoming infinite. The alternative characterization that we adopt in this paper is a stationary distribution of human capital for which the wage premium remains bounded despite continual advances in new technology that are embodied into the capital stock. Note that we are not arguing that the mean skills of the workforce do not improve over time, as postulated for example in the Lucas (1988)-Uzawa (1965) models of endogenous growth. We are arguing that it makes little sense to require that the distribution of skills become degenerate asymptotically.
} 
PRODUCTIVITY SHOCKS IN A MODEL WITH VINTAGE CAPITAL AND HETEROGENEOUS LABOR

nearly as much during the second half of the 1990s, which is a period of unusually high productivity growth. This high productivity growth is generally attributed to the IT revolution, which is probably the most significant example of embodied technical change in the last few decades. Similarly, the 1960s are a period of high productivity growth as well, but Figure 1 shows that the wage premium did not increase very much over this period either.

\section{[FIG 1: LOG OF THE 90-10 WAGE PREMIUM]}

The fact that the wage premium did not rise in the 1960s could reflect a difference in the kind of productivity shocks that hit the economy at that time. It could be argued, for instance, that while embodied technology shocks raise the wage premium, disembodied shocks do not. However, our model provides evidence against this intuition. It turns out that firms respond to a disembodied technology shock by reallocating labor away from the newest vintage and towards the oldest vintage. This has the effect of raising the marginal product of labor on the newest vintage relative to the other vintages. Thus, the wage premium goes up in response to disembodied technology shocks as well. And while the parameterization of our model suggests that the increase in the wage premium due to disembodied technology shocks is not as large as that due to embodied technology shocks (of the same size), a key implication is that an increase in the wage premium (even when accompanied by an increase in productivity) cannot be used to argue that the economy has been hit by an embodied productivity shock. The model suggests that such a determination can only be made by looking at what has happened to the amount of labor employed in different jobs.

In any case, productivity shocks do not lead to changes in the wage premium that are anywhere near the magnitude observed in the data, suggesting that other factors (such as changes in the skill distribution 
of labor) are likely to be behind the observed changes in the skill premium. ${ }^{5}$ Consequently, in the final section of our paper we pose the question of whether an exogenous increase in the variation of worker skills, or a shift toward a more heterogeneous workforce that maintains the same stock of human capital in the economy, could account for the observed sizable increase in wage dispersion that occurred in the United States during the 1980s and 1990s. We find that a calibration of the model can easily be found which is consistent with that change. This increase in wage dispersion has no effect on consumption, investment, and output.

Our second issue concerns differences in the way that different kinds of technology shocks affect key macroeconomic variables. Gilchrist and Williams (GW) (2000) and Benhabib and Hobijn (BH) (2001) have shown that vintage capital models (with undifferentiated labor) are better able to reproduce important dynamic relationships in the economy than the standard RBC model. These include "hump-shaped" responses of employment and output to technology shocks, and, as emphasized by GW, a weaker initial effect of the shock on employment followed by a more drawn out return to the long-run equilibrium. BH focus on the possibility that an acceleration in the rate of technological advance could induce an investment boom in the economy analogous to what appears to have characterized the U.S. economy in the late 1990s. This result relies on an increase in the savings rate resulting from an increase in the pace of embodied technological progress, which sets the economy off on a permanently higher growth path for investment and output.

We find that many of the predictions concerning the short-run dynamics of the vintage capital models of GW and $\mathrm{BH}$ described above carry over to our model, though these dynamics become more complex. In the short run, the savings rate rises in response to permanent shocks to embodied technology, while it falls in response to permanent

\footnotetext{
${ }^{5}$ See Card and DiNardo (2002) for arguments against assigning technology the major role in the recent rise in the wage premium.
} 
PRODUCTIVITY SHOCKS IN A MODEL WITH VINTAGE CAPITAL AND HETEROGENEOUS LABOR

shocks to disembodied technology. These different responses are due to the fact that the disembodied technology shock is realized across all vintages of capital and induces a wealth response on the part of households, whereby they wish to increase their consumption at the expense of investment, creating a consumption boom until the persistence in the shock dies out. In contrast, a permanent shock to embodied technology carries with it a transitory component that temporarily steepens the quality gradient across vintages of capital until the new technology has worked its way across all vintages. The households respond in the short run with a dominant substitution effect that reduces consumption's share of output, thus increasing the savings rate, and bringing about an investment boom. This response dies out as the persistence in the shock subsides.

However, unlike $\mathrm{BH}$, we find that the steady-state savings rate declines as more of the economy's productivity growth comes from embodied rather than disembodied technology. The reallocation of workers across machines plays a role here as well; households take advantage of the steeper quality gradient that a more rapid development of embodied technology affords by shifting the allocation of workers away from the older technology and toward the newer technology, thus enhancing the efficacy of the economy's human capital in production. This allows consumption to rise without requiring higher levels of output, and hence a greater work effort.

\section{Theoretical Model}

The model makes use of the Lucas (1980) "multimember household" abstraction to capture the heterogeneity of the workforce, where there is a distribution of workers across a skill continuum of measure one. The workers offer their labor services to an aggregate firm that operates multiple production processes, each with a different vintage of capital. The firm assigns worker groups to production processes according to a matching rule that preserves an ordering of workers with 
the highest-skilled group of workers assigned to the latest vintage of capital, the next highest-skilled group assigned to the second newest vintage of capital, etc. As Jovanovic(1998) points out "It is plausible and empirically well founded to suppose that new technologies and skills are complements, and so the new machines will be used by the most skilled workers." We further assume that the workers in each group who are assigned to work in the same production process (i.e., with the same vintage of capital) receive the same wage. The wage rate is based on the average labor quality of the group as a whole.

Growth in the economy results from both improvements in disembodied technology, which affects all production processes symmetrically, and embodied technological progress, which differentially affects productivity across the production processes by determining the quality of the latest vintage. We assume that the number of vintages in the economy is fixed, and enforced by an exogenous scrappage rule under which the price of the oldest vintage of capital when it is sold for scrap is determined. This price is taken to be a one-period projection from the price of the oldest vintage based on the schedule of equilibrium prices of capital stocks for which there are markets. This schedule of prices declines with vintage.

\subsection{Production with Vintage Capital and the Determinants of Growth}

The production technology that we employ is linearly additive across production processes that themselves are Cobb-Douglas in capital and effective units of labor. ${ }^{6}$ The capital employed by each production process is of a separate vintage, denoted $j=1 \ldots T$, with the stock of the latest vintage of capital in production at date $t$ designated $K_{t}^{1}$ and the oldest vintage designated $K_{t}^{T}$.

\footnotetext{
${ }^{6}$ There is a literature on "jelly capital" in which an aggregation of capital across vintages is possible when complementarities may be present across the differentiated production processes that employ capital of a different vintage. See, e.g., Phelps (1962) and Benhabib and Hobijn (2001). The linearly additive production process that we utilize is a particular parameterization of those models in which the elasticity of substitution across production processes is one.
} 
$F\left(K_{t}^{j}, H_{t}^{j} ; \mu_{t}, A_{t-j}\right)=\mu_{t} \sum_{j=1}^{T}\left(K_{t}^{j}\right)^{\alpha}\left(A_{t-j} H_{t}^{j}\right)^{1-\alpha}, \alpha \in(0,1), j=1 \ldots T$

In this expression, each vintage has a level of embodied technology attached to it. This is captured by the term $A_{t-j}$ and contributes to the productivity of labor by scaling up each unit of human capital, $H_{t}^{j}$, assigned to work with that vintage of capital. Human capital incorporates a quality adjustment to hours worked, as described in the next subsection. Therefore, there are two enhancements to hours worked assigned to any particular production process: one coming from embodied technological progress and the other from the average skill level of that particular group of workers, whose composition is endogenously determined.

The two sources of long-run productivity growth are embodied technological change, $\gamma_{t}$, or the gross growth rate of $A_{t}$, where the current history of these technological improvements is given by the sequence:

$$
\gamma_{t-j}=\left(\frac{A_{t-j}}{A_{t-j-1}}\right), \quad j=1 \ldots T
$$

and the gross growth rate of disembodied technology, $g_{t}$, where:

$$
g_{t}=\left(\frac{\mu_{t}}{\mu_{t-1}}\right)
$$

To work with a stationary model, we employ the following useful normalization. Define the normalized capital stocks to be:

$$
\tilde{K}_{t}^{j}=\left(\frac{K_{t}^{j}}{\Omega_{t-j}}\right), \quad j=1 \ldots T
$$


where the latest vintage of capital is normalized on the current level of disembodied technology and the level of embodied technology associated with the oldest vintage of capital used in current production, or:

$$
\Omega_{t-1}=\mu_{t}^{\frac{1}{1-\alpha}} A_{t-T}
$$

and more generally for any given vintage $j$ :

$$
\Omega_{t-j}=\mu_{t}^{\frac{1}{1-\alpha}} A_{t-T-j+1}
$$

The normalized production function is given by:

$$
F\left(\tilde{K}_{t}^{j}, H_{t}^{j} ; G_{t-i}, \Gamma_{t-j}\right)=\sum_{j=1}^{T}\left(\frac{\tilde{K}_{t}^{j}}{\prod_{i=0}^{j-2} G_{t-i}}\right)^{\alpha}\left(\Gamma_{t}^{j} H_{t}^{j}\right)^{1-\alpha}, \alpha \in(0,1), j=1 \ldots T
$$

where we define:

$$
G_{t-i}=\left(\frac{\Omega_{t-i-1}}{\Omega_{t-i-2}}\right)
$$

(with $\prod_{i=0}^{-1} G_{t-i}=1$ ). The level of embodied technology in the $j$ th vintage of capital relative to the level of embodied technology in the oldest (Tth) vintage is given by:

$$
\Gamma_{t}^{j}=\left(\frac{A_{t-j}}{A_{t-T}}\right), j=1 \ldots T
$$

Note that:

$$
\Gamma_{t}^{1}>\Gamma_{t}^{2}>\ldots>\Gamma_{t}^{T}=1
$$


PRODUCTIVITY SHOCKS IN A MODEL WITH VINTAGE CAPITAL AND HETEROGENEOUS LABOR

which fully captures the "quality gradient" in capital across vintages. The more rapid is the pace of embodied technological progress, the steeper is this "quality gradient."

As will become apparent below, under this normalization, the equilibrium gross growth rate of the economy at date $t$ is simply given by $G_{t}$, and can be expressed as the following combination of disembodied and embodied technological progress:

$$
G_{t}=g_{t}^{\frac{1}{1-\alpha}} \gamma_{t-T}
$$

\subsection{Workforce Heterogeneity}

The multimember household has a continuum of $\mathrm{P}$ workers indexed by $x$, and distributed uniformly along the unit interval: $x \in[0,1]$. The skill level of a worker with index $x$ is denoted by the function $h(x)$, which determines the quality-adjustment to the units of labor supplied by that worker such that the most highly skilled workers have an index value of $x=0$ and a skill level of $h(0)$, while the least-skilled workers have an index value of $x=1$ and a skill level of $h(1)$.

It is assumed that the labor-leisure decision is collectively taken by the household, with all workers choosing the same fraction of leisure time, denoted $l_{t}$, and labor, denoted $z_{t}$. The household's total leisure time for all workers is given by $L_{t}=P l_{t}$. With the time allocation decision for each worker given by $z_{t}+l_{t} \leq 1$, the total amount of time allocated to labor is:

$$
P z_{t}=P-L_{t}
$$

Given a discrete (and constant) number of vintages of capital, denoted $T$, in use at any point in time, the quality-adjusted units of labor, or human capital, that are allocated to vintage $j$ are given by: 


$$
\begin{gathered}
H_{t}^{j}=P z_{t} \int_{x_{t}^{j-1}}^{x_{t}^{j}} h(x) d x \\
=\left.P z_{t} \chi(x)\right|_{x_{t}^{j-1}} ^{x_{t}^{j}}=P z_{t}\left[\chi\left(x_{t}^{j}\right)-\chi\left(x_{t}^{j-1}\right)\right], \quad j=1, \ldots, T
\end{gathered}
$$

where $z_{t} \chi(x)$ is the cumulative distribution of human capital per capita employed at date t. The total number of hours worked by workers assigned to capital of vintage $j$ is given by:

$$
N_{t}^{j}=P z_{t} \int_{x_{t}^{j-1}}^{x_{t}^{j}} d x=P z_{t}\left[x_{t}^{j}-x_{t}^{j-1}\right], \quad j=1 \ldots T
$$

\subsection{Household Optimization}

A schedule of prices of the various vintages of capital goods is required to establish the scrappage rule. Therefore, we choose to place the ownership of the capital goods with the household, and employ a Lucas (1978)-style asset pricing formulation. We also have chosen to have the household select contingent group employment decision rules by partitioning $x$ into $T$ worker groups of contiguous skill levels, denoted $\hat{x}_{t}^{j}=x_{t}^{j}-x_{t}^{j-1}, j=1 \ldots T$ that are being offered to the firm. Given the skill profile of the household's workers within each group, these choices are constrained by the "matching rule" (of "best workers" with the "best machines") and determined in equilibrium by the firm's demand for units of quality-adjusted labor, $H_{t}^{j}, j=1 \ldots T$. The household also makes its consumption/savings and labor/leisure decisions.

The household's optimization problem is:

$$
\max _{\left\{c_{t}, L_{t}, \hat{x}_{t}^{j}, H_{t}^{j}, K_{t+1}^{j}\right\}} E_{0} \sum_{t=0}^{\infty} \beta U\left(c_{t}, L_{t}\right), \quad j=1 \ldots T \quad \beta \in(0,1)
$$


PRODUCTIVITY SHOCKS IN A MODEL WITH VINTAGE CAPITAL AND HETEROGENEOUS LABOIR

where the household's consumption is $c_{t}$ and its capital holdings are $\left\{K_{t}^{j}\right\}_{j=1}^{T}$, whose values are given at date $\mathrm{t}=0$ when the optimization is conducted.

Each period, the household faces a budget constraint:

$c_{t}+K_{t+1}^{1}+\sum_{j=1}^{T-1} p_{t}^{j} K_{t+1}^{j+1} \leq \sum_{t=0}^{T} R_{t}^{j} K_{t}^{j}+\sum_{t=0}^{T} W_{t}^{j} H_{t}^{j}+\sum_{t=1}^{T} p_{t}^{j}(1-\delta) K_{t}^{j}, \quad \delta \in(0,1)$

under which the household combines: its capital income, where $R_{t}^{j}$ is the rental rate on a unit of the $j$ th vintage of capital; its labor income, where $W_{t}^{j}$ is the wage rate per unit of quality-adjusted labor (or human capital) assigned to the $j$ th production process; and its revenue from the sale of its capital holdings, where $p_{t}^{j}$ is the market price of the $j$ th vintage of capital at date $t$ and $\delta$ is the depreciation rate, in order to: make its consumption purchases; complete its new investment in the latest vintage of capital, $K_{t+1}^{1}$, which it will rent to the firm beginning in period $t+1$; and acquire its holdings of used capital to be carried over to next period.

The household's labor supply decisions are further constrained by its total available human capital and the matching rule, such that:

$$
H_{t}^{j}=P z_{t}\left[\chi\left(x_{t}^{i}\right)-\chi\left(x_{t}^{i-1}\right)\right], \quad j=1, \ldots, T
$$

and

$$
\sum_{j=1}^{T} \hat{x}_{t}^{j}=\sum_{j=1}^{T}\left[x_{t}^{i}-x_{t}^{i-1}\right]=1
$$

It also faces the time resource constraint:

$$
z_{t}+\frac{L_{t}}{P} \leq 1
$$


After normalizing the household's problem on $\Omega_{t-j}$, and defining the normalized variables $\tilde{c}_{t}=\left(\frac{c_{t}}{\Omega_{t-1}}\right)$ and $\tilde{w}_{t}^{j}=\left(\frac{W_{t}^{j}}{\Omega_{t-1}}\right)$, the Euler equations become:

$$
\begin{gathered}
\beta E\left\{\left(\frac{U_{\tilde{c}_{t+1}}}{U_{\tilde{c}_{t}}}\right)\left[\frac{R_{t+1}^{j+1}+p_{t+1}^{j+1}(1-\delta)}{G_{t+1} p_{t}^{j}}\right]\right\}=1, \quad p_{t}^{0}=1, \quad j=0 \ldots(T-1) \\
\tilde{w}_{t}^{j}=\tilde{w}_{t}^{j-1}, \quad j=1 \ldots T \\
U_{\tilde{c}_{t}} \sum_{j=1}^{T} H_{t}^{j} \tilde{w}_{t}^{j}=z_{t} P U_{L_{t}}
\end{gathered}
$$

Equation (20) is the collection of familiar asset pricing equations for those vintages of capital for which there is a market. This excludes vintage $T$, which is scrapped at the end of the period. Equation (21) equates the wage rate paid per unit of human capital (quality-adjusted labor) across all worker groups. (Hourly wages and the wage premium are discussed below.) Equation (22) is the optimal labor/leisure decision that holds for all workers.

\subsection{Firm's Optimization}

The firm is assumed to be competitive in the factor and product markets. It rents physical capital of all vintages from households and hires quality-adjusted units of labor that are sorted into worker groups and matched with capital vintages by quality. Each member of a given group works in the same production process and receives the same wage. The firm performs the following static period-by-period profitmaximization: 
PRODUCTIVITY SHOCKS IN A MODEL WITH VINTAGE CAPITAL AND HETEROGENEOUS LABOR

$$
\max _{K_{t}^{j}, H_{t}^{j}}\left[\mu_{t} \sum_{j=1}^{T}\left(K_{t}^{j}\right)^{\alpha}\left(A_{t-j} H_{t}^{j}\right)^{(1-\alpha)}-\sum_{i=1}^{T} R_{t}^{j} K_{t}^{j}-\sum_{j=1}^{T} W_{t}^{j} H_{t}^{j}\right], \quad j=1 \ldots T
$$

where period profits are expressed as output less the factor payments.

After normalizing on $\Omega_{t-j}$, the firm's first-order conditions yield a set of expressions where each factor payment is equated to the factor's marginal product.

$$
\begin{gathered}
\alpha\left(\frac{\tilde{K}_{t}^{j}}{H_{t}^{j}}\right)^{\alpha-1}\left(\prod_{i=0}^{j-2} G_{t-i}\right)^{1-\alpha}\left(\Gamma_{t}^{j}\right)^{1-\alpha}=R_{t}^{j}, \quad j=1 \ldots T \\
(1-\alpha)\left(\frac{\tilde{K}_{t}^{j}}{H_{t}^{j}}\right)^{\alpha}\left(\prod_{i=0}^{j-2} G_{t-i}\right)^{-\alpha}\left(\Gamma_{t}^{j}\right)^{1-\alpha}=\tilde{w}_{t}^{j}, \quad j=1 \ldots T
\end{gathered}
$$

Note that the normalized wage rates on quality-adjusted labor, or human capital, $\tilde{w}_{t}^{j}$, tend to be positively affected by embodied technology, as indicated by $\Gamma_{t}^{j}$, the quality gradient on vintage capital. The implication is that the firm will wish to increase the labor allocation to later vintages that possess a higher level of embodied technology. This effect becomes more pronounced as the quality gradient steepens.

The "hourly" wages paid to each worker can be determined by first computing the equilibrium normalized wage bill paid by the firm to each worker group. For the production process employing vintage $j$ capital, the normalized wage bill is $\tilde{w}_{t}^{j} H_{t}^{j}$, where $H_{t}^{j}$ equals the total quality-adjusted units of labor employed. The average normalized hourly wage rate for workers assigned to vintage $j$ capital is $\tilde{v}_{t}^{j}=\tilde{w}_{t}^{j} H_{t}^{j} / N_{t}^{j}$. The corresponding hourly wage rate is $v_{t}^{j}=\Omega_{t-1} \tilde{v}_{t}^{j}$. Note that, whereas a steepening of the quality gradient of capital across vintages tends to increase the wage differentials across worker groups, a 
reallocation of workers toward the latest vintages has the effect of lowering the average quality of workers in every worker group, and thus tending to lower wages economy-wide.

One measure of the "wage premium" paid to workers assigned to more recent vintages of capital is the ratio of the wage rate per worker for that $(j)$ vintage to the wage rate per worker for the least-skilled workers utilizing the oldest vintage, or $\tilde{v}_{t}^{j} / \tilde{v}_{t}^{T}$. The wage premium paid to the most highly skilled workers relative to the least skilled is $\tilde{v}_{t}^{1} / \tilde{v}_{t}^{T}$. A steeper quality gradient across capital vintages will tend to raise the wage premium, while a reallocation of workers toward the latest vintages will tend to reduce the wage premium.

\subsection{Equilibrium}

Equilibrium in the goods market consists of transforming output goods along with the scrapped capital of vintage $T$, the sum of which is defined as normalized output, $\tilde{y}_{t}$, into consumption and new investment. After normalizing,

$$
\tilde{c}_{t}+\tilde{i}_{t}=\tilde{y}_{t}=\sum_{j=1}^{T}\left(\frac{\tilde{K}_{t}^{j}}{\prod_{i=0}^{j-2} G_{t-i}}\right)^{\alpha}\left(\Gamma_{t}^{j} H_{t}^{j}\right)^{1-\alpha}+p_{t}^{T}(1-\delta)\left(\frac{\tilde{K}_{t}^{T}}{\prod_{i=0}^{T-2} G_{t-i}}\right)
$$

where normalized investment is given by: $\tilde{i}_{t}=G_{t+1} \tilde{K}_{t+1}^{1}$, and the undepreciated portion of the oldest vintage of capital is sold at the end of the period for a unit price of $p_{t}^{T}$ as determined by the exogenous scrappage rule ${ }^{7}$ :

\footnotetext{
${ }^{7}$ Gilchrist and Williams (2000) endogenize the scrappage decision in a vintage capital model. However, they achieve endogenous scrappage by relying on an ex post Leontieff technology, with a "one-man-one-machine" constraint that does not allow for an optimal ex post reallocation of workers across vintages to be characterized by endogenous capital-labor ratios. This modeling choice is unsuitable for our purposes, since an optimal deployment of a heterogeneous workforce across vintages of capital is essential to the issues addressed in this paper.
} 
PRODUCTIVITY SHOCKS IN A MODEL WITH VINTAGE CAPITAL AND HETEROGENEOUS LABOR

$$
\frac{p_{t}^{T}}{p_{t}^{T-1}}=\frac{p_{t}^{T-1}}{p_{t}^{T-2}}
$$

The evolution of the normalized capital stocks is given by:

$$
\tilde{K}_{t+1}^{j+1}=(1-\delta) \tilde{K}_{t}^{j}
$$

with an associated movement down the quality gradient, from $\Gamma_{t-1}^{j}$ to $\Gamma_{t}^{j+1}$, reflecting the aging of the technology embodied in the capital stock.

\section{Calibration Issues}

To calibrate the model, choices must be made for the utility function, $U(c, L)$ and the distribution of skills, $h(x)$. The utility function, expressed in terms of normalized consumption is assumed to be loglinear:

$$
U\left(\tilde{c}_{t}, L_{t} ; \Omega_{t-1}\right)=\ln \left(\Omega_{t-1} \tilde{c}_{t}\right)+\eta \ln L_{t}, \eta>0
$$

For the distribution of skills, an exponential function was found to fit well the empirical distribution of human capital estimated by Abowd, Lengermann, and McKinney (2002). Their estimates are based on the Longitudinal Employer-Household Dynamics (LEHD) Program data for $1992 .^{8}$ The empirical model is:

$$
h(x)=S_{0} e^{\phi(1-x)}, \quad S_{0}, \phi>0
$$

\footnotetext{
${ }^{8}$ These data cover California, Illinois, Michigan, and North Carolina for the 1st quarter, and include over 400,000 observations. See Abowd, Lengermann, and McKinney (2002), Table 9.
} 
and the estimated values were: $S_{0}=8.92$ and $\phi=2.187 .{ }^{9}$ Figure 2 displays the values from Abowd, et. al. together with the fitted values from the regression.

\section{[FIG 2: DISTRIBUTION OF HUMAN CAPITAL]}

\subsection{Steady-State Model}

The model is solved for a small set of vintages, $T=3$, which is sufficient to highlight the basic properties of the model. In the steady-state, normalized version of the model, there are: 21 endogenous variables, $H^{j}, x^{j}, L, z, p^{j}, r^{j}, \tilde{c}, \tilde{K}^{j}, \tilde{w}^{j}, j=1 \ldots 3$, where the net real rental rates on capital $\tilde{K}^{j}, j=1 \ldots 3$ are given by $r^{j}=R^{j}-\delta, j=1 \ldots 3 ; 4$ exogenous variables $\Gamma^{j}, G, \quad j=1 \ldots 3$; and 7 parameters, $A, \phi, \beta, \delta, \eta, \alpha, P$. Therefore, 11 constraints are needed to solve the model. We make the following selections. $S_{0}$ and $\phi$ are estimated as described above. Capital's share of income is set to $\alpha=0.33$. Having limited the number of vintages to $T=3$, the depreciation rate is set to $\delta=1 / T{ }^{10}$ The population of workers is an exogenous scale variable in the model that is set to $P=100$. The annualized gross growth rate of the economy is set to $G=1.025$, of which 60 percent is attributed to embodied technological progress, or $\Gamma^{j}=1.015, j=1,2,3$. The contribution of embodied technology to growth is consistent with Greenwood, Hercowitz, and Krusell (1997), who relied on Gordon's (1990) relative price series for producer durables versus consumer nondurables and services, and with Gilchrist and Williams who estimated the contribution of embodied technology in a combined "putty-clay"-Solow vintage capital model to be between 50 and 70 percent, and it is similar to the $2 / 3$ estimate

\footnotetext{
${ }^{9}$ The estimated regression was $L h c=9.21+0.0219 P e$, where $L h c$ denotes the log of the dollar value of human capital and $P e$ denotes the percentile of the human capital distribution. The equation had an adjusted- $R^{2}$ of 0.98 .

${ }^{10}$ This assumption yields very high rental rates on capital, but avoids excessively high scrappage values. With extraordinary complications to the model, $T$ could be increased sufficiently to bring $\delta$ down to reasonable levels. However, this should not change the qualitative properties of the model that we wish to highlight.
} 
PRODUCTIVITY SHOCKS IN A MODEL WITH VINTAGE CAPITAL AND HETEROGENEOUS LABOIK of Wilson (2000) based on estimates of production functions for the manufacturing sector.

The remaining parameters, $\beta=0.9847$, and $\eta=1.7437$, were chosen to be consistent with a 40-hour workweek $(z=0.36)$ and a real net rental rate on the most recent vintage of capital of 6.08 percent, which is broadly consistent with the long-run return on U.S. equities [see Mehra and Prescott (1985)]. As a check on our calibration, we computed the equivalent of the 90-10 wage premium in our model to be $\frac{\tilde{v}^{1}}{\tilde{v}^{3}}=1.408$ and plotted this number (which is based on data for 1992) on the graph displaying the actual 90-10 wage premium in Figure 1. The model generated value turns out to be quite close to the data.

Table 1 reports a summary of the parameters and steady-state values derived from this calibration exercise that we use as the "benchmark" in subsequent exercises.

[INSERT TABLE 1: Benchmark Parameters and Steady-State Values]

To solve the stochastic version of the model and run dynamic simulations, characterizations of the stochastic processes driving the two sources of productivity growth are needed. We assumed $\operatorname{ARIMA}(1,1,0)$ processes for each, reflecting the fact that a time series on average productivity is well characterized by such a process. However, little guidance is available on how the variance of productivity growth should be decomposed between disembodied technology shocks $(\mu)$ and embodied technological progress $(A)$. For the purposes of this paper, we assumed the processes to be symmetric, apart from their respective trends.

From equation (11), the stochastic process for $G_{t}$ is thus derived from the processes for $\mu_{t}$ and $A_{t}$ as follows:

$$
\ln g_{t}=\left(1-\rho_{m}\right) \ln \bar{g}+\rho_{m} \ln g_{t-1}+\epsilon_{t}, \quad \rho_{m} \in[0,1), \quad \epsilon_{t} \sim N\left(0, \sigma_{m}^{2}\right)
$$


$\ln \gamma_{t}=\left(1-\rho_{A}\right) \ln \bar{\gamma}+\rho_{A} \ln \gamma_{t-1}+\nu_{t}, \quad \rho_{A} \in[0,1), \quad \nu_{t} \sim N\left(0, \sigma_{A}^{2}\right)$

where $\epsilon$ is the growth rate shock to disembodied technology, and $\nu$ is the growth rate shock to embodied technology. Then, from equations (11), (31), and (32):

$$
\ln G_{t+1}=\ln \left(\frac{\Omega_{t+1}}{\Omega_{t}}\right)=(1-\alpha)^{-1} \ln g_{t+1}+\ln \gamma_{t-T+1}
$$

and the mean gross growth rate for the economy, $\bar{G}$, is given by:

$$
\bar{G}=\bar{g}^{\frac{1}{1-\alpha}} \bar{\gamma}
$$

The stochastic model was estimated using the undetermined coefficients method described in Christiano (2002). For the simulation exercises, we set $\sigma_{A}=(1-\alpha)^{-1} \sigma_{m}=0.020$, which approximates the percent standard deviation of the annual growth rate of output for the U.S. economy over the period 1963-2002 (where the sample has been selected to match the wage data). For the persistence parameters, we searched over the range of values $\rho_{A}, \rho_{m} \in[0,1)$, and computed the selected second moments from the data for each pair based on a sample of trial runs involving 5000 replications of length 39 (to match the sample period). The results are broadly consistent with those reported in Gilchrist and Williams (2000) and are not reported in the paper, but are available from the authors on request. 
PRODUCTIVITY SHOCKS IN A MODEL WITH VINTAGE CAPITAL AND HETEROGENEOUS LABOIR

\section{The Effects of Embodied Versus Disembodied Technical Change}

This section reports on exercises designed to examine two issues concerning the nature of productivity growth. The first set of exercises focuses on the consequences of shifting the overall composition of the sources of long-run steady-state growth from the benchmark settings of 60 percent embodied technology/40 percent disembodied technology to 100 percent embodied technology. This shift in the sources of productivity growth results in a steepening of the quality gradient across vintages of capital and induces a reallocation of labor toward the more recent vintage with very little change in employment. The "level effects" that the economy experiences include a decline in aggregate output that is accompanied by a significant reduction in the savings rate that enables aggregate consumption to rise.

The second set of exercises compares the dynamic responses of the economy to the two sets of shocks. The wage premium goes up after the embodied technology shock, but this increase is temporary and does not appear to be large enough to explain the increase observed in the U.S. Somewhat surprisingly, the wage premium goes up after a disembodied technology shock as well. By contrast, the responses of output, investment and consumption to the two shocks turn out to be qualitatively different, due to the transitory aspect of (permanent) shocks to embodied technology that is absent in the shocks to disembodied technology.

\subsection{Steady State Effects of Changes in the Source of Growth}

Using the benchmark parameter settings, and maintaining a longrun growth rate of 2.5 percent $(\bar{G}=1.025)$, the long-run balanced growth properties of the model are computed for an economy in which growth is assumed to come entirely from embodied technical progress (that is, an economy where $\bar{\gamma}=1.025$ ). The results are compared to the benchmark values in Table 2 . 
[INSERT TABLE 2, STEADY-STATE COMPARISONS WITH $100 \%$ EMBODIED TECH GROWTH]

Along the new long-run growth path, neither the normalized level of consumption nor output are affected very significantly, with the former rising by four-tenths of a percent while the latter falls by three tenths of a percent. This discrepancy is attributable to investment, which declines by about 1-1/2 percent. Consistent with this decline, the savings rate falls by slightly more than 1 percent as well. Note that this is in contrast to the findings of Benhabib and Hobijn (2001) who find that (in a model with vintage capital and a homogenous labor force) both the savings rate and investment rise when the pace of embodied technical progress goes up. In our model, a steepening of the quality gradient of capital leads to a reallocation of labor towards the newest vintage, which allows for a more efficient use of the economy's heterogenous labor stock. (Table 2 shows that the employment share allocated to the newest vintage rises by nearly 2 percent while that allocated to the oldest vintage falls by more than 1-1/2 percent.) In equilibrium, households increase consumption somewhat and allow investment to fall by more.

As expected, the steeper capital quality gradient is also reflected in a change in the relative rental rates on the different vintages of capital, with the rental rate on the newest vintage rising by more than 1 percentage point while the rental on the oldest vintage falls slightly. Perhaps more surprising is the finding that all three wage rates-including the wage rate for workers on the newest vintage- in the model decrease. Two offsetting forces are at work on the wages of workers assigned to the newest vintage. By itself, the steeper capital-quality gradient tends to push up the wages of these workers. However, the workers that are newly assigned to the latest vintage have lower human capital than the workers already working on these machines, and this tends to reduce the average wages for this group. Hourly wages fall for workers on other vintages as well, reflecting the reallocation of the relatively 
PRODUCTIVITY SHOCKS IN A MODEL WITH VINTAGE CAPITAL AND HETEROGENEOUS LABOथ

higher skilled workers towards the newer vintages. The net effect is a small increase in the wage premium.

\subsection{Comparing the Response of the Economy to Permanent Shocks to} Embodied versus Disembodied Technology

Growth rate shocks to embodied and disembodied technology are assumed to contribute equally to the variance of output in the benchmark model. The processes are assumed to be symmetric, with persistence parameters of 0.2 , which is the estimate one obtains when real output growth is regressed on its own lag over our 40 year sample period.

The qualitatively different responses of the savings rate to the two permanent shocks are illustrated in the top panel of Figure 3, which displays the impulse response functions resulting from one-standard deviation shocks to embodied (solid lines) and disembodied technology (dashed lines). A permanent (positive) shock to embodied technology leads to an increase in the savings rate during the first two periods, as this is the period during which an investment in new capital with improved technology can temporarily exploit the steeper vintage-capital quality gradient. The increase in investment can be seen in the middle panel of Figure 3. Investment falls off because the steeper quality gradient eventually dissipates once the shock has reached the oldest vintage. The lowest panel of the figure shows that part of the increase in investment following an embodied technology shock is achieved by a drop in consumption during the first two periods. In contrast, the permanent disembodied technology shock induces an increase in consumption (middle panel of figure 3) which is accommodated partly by a reduction in the savings rate and investment.

This figure illustrates a key difference in the response of the economy to these shocks: A permanent shock to embodied technology elicits an investment boom, with the savings rate rising while a permanent shock to disembodied technology is followed by a consumption boom, with a declining savings rate. These differential responses owe to the fact 
that, unlike a permanent shock to disembodied technology, a permanent shock to embodied technology has a transitory component associated with it, as the improved technology works its way through the vintages of capital over time. This transitory feature of the shock strengthens the substitution effect relative to the wealth effect and provides a greater incentive to invest. The disembodied technology shock has no such temporary character, as it simultaneously affects all production processes in a similar manner. The optimal response of the household is to increase consumption, as the wealth effect dominates the substitution effect in the consumption-savings decision.

[INSERT FIGURE 3: RESPONSE OF SAVINGS, INVESTMENT, CONSUMPTION]

\section{[INSERT FIGURE 4: RESPONSE OF OUTPUT AND EMPLOY-} MENT]

Figure 4 illustrates the output and employment responses to permanent embodied and disembodied technology shocks. As the top panel indicates, both kinds of shocks tend to push up output, though the effect of embodied technology shocks is larger and more persistent. The same thing is true in the labor market. While the initial response of total labor hours to an embodied technology shock is similar in magnitude to the disembodied technology shock, the embodied technology shock has a more persistent effect. This would suggest that strength in the labor market should be evident for a more extended period of time following an investment boom than would would observe following a consumption boom. ${ }^{11}$

[INSERT FIGURE 5: LABOR ALLOCATIONS AND WAGE PREMIUM]

\footnotetext{
${ }^{11}$ It appears that the persistence in the strong labor market response would be enhanced in this model if the number of vintages of capital were increased.
} 
PRODUCTIVITY SHOCKS IN A MODEL WITH VINTAGE CAPITAL AND HETEROGENEOUS LABO2R

Figure 5 shows what happens to the allocations of labor (hours) across the different vintages of capital and to the wage premium in response to the two kinds of technology shocks. In response to an embodied technology shock, labor gets allocated toward the newest vintage (panel A) and away from the oldest capital vintage (panel $\mathrm{C}$ ). This response is pronounced for periods 2 and 3 when the results of capital investment decisions associated with the improved technology are differentially affecting the vintages of capital to the greatest extent. The response to a permanent disembodied technology shock tends to be more muted in terms of the skill allocations across vintages, but the direction of reallocation is the opposite of that which takes place in response to embodied technology shocks.

As expected, both shocks tend to push up wages. The permanent nature of the productivity shocks, whether to embodied or disembodied technology, induces an upward shift of the growth path for wages that benefits all workers. With the size of the shocks identical, the longrun effects on wages are identical. There is a difference in the short run response, though. Following an embodied technology shock, the premium paid to workers utilizing the most recent vintage of capital relative to those assigned to the oldest vintage increases, with a spike in that measure of the wage premium evident in period 3 (see panel D of Figure 5). Period 3 is the last period for which the embodied technology has not influenced all vintages. It is the period when workers who are assigned to the oldest vintages are at the greatest disadvantage and this disadvantage is reflected in their productivity, and hence in their wages. The wage premium tends to go up after an embodied technology shock as well, though the increase is noticeably smaller.

[INSERT FIGURE 6: LABOR AND WAGES RESPONSES TO A SEQUENCE OF SHOCKS]

To highlight the differences in labor re-allocation in response to the two kinds of shocks, Figure 6 shows what would happen if the economy 
were to be hit by a sequence of five shocks, similar, perhaps to what might have happened during the late 1990s. Embodied technology shocks lead to a pronounced reallocation of labor away from the oldest vintage, while the labor allocated to both the newest and the middle vintage goes up. The wage premium goes up as well. By contrast, labor gets reallocated in the reverse direction following a disembodied technology shock. This reallocation seems surprising at first glance, since the disembodied technology shock affects all vintages equally. However, the fact that all vintages are affected equally means that the disembodied technology shock changes the productivity of the newest vintage relative to the oldest vintage, and so causes a reallocation of labor.

The disembodied technology shock also causes an increase in the wage premium. Though this increase is not as large as that which results from an embodied technology shock, it does have the interesting implication that a higher wage premium - even when accompanied by rising productivity - can not be interpreted as conclusive evidence of embodied technical change. In our model, the two shocks are distinguished by what happens to employment across the different vintages, which suggests that one should look at employment across skill levels to determine the nature of the underlying shock.

\section{Workforce Heterogeneity and the Wage Premium}

While the evidence in the previous section suggests that faster technological progress will tend to push up the wage premium, the increases we obtain are neither very large nor very long lived. This suggests that labor demand factors that are technology-driven are not likely to produce the very large increases in wage dispersion that was observed in the U.S. economy during the 1980 s and 1990 s. $^{12}$

\footnotetext{
12 As discussed above, KORV argue that complementarities between skilled labor and producer durables in production may be capable of explaining the wage premium between 1960 and 1985 . We do not explore this possibility in our model.
} 
PRODUCTIVITY SHOCKS IN A MODEL WITH VINTAGE CAPITAL AND HETEROGENEOUS LABOQR

This section looks to the supply side of the labor market for an alternative mechanism that could induce large changes in wage dispersion. It turns out that the introduction of greater heterogeneity into the distribution of skills across workers, while the aggregate stock of human capital in the economy is held fixed, leads to a significant increase in wage dispersion, with very little or no consequence for the macroeconomy.

In the experiment that we conduct, all parameter values are fixed at their benchmark settings, except those that determine the distribution of human capital, ie., $S_{0}$ and $\phi$. These two parameters are adjusted to match as nearly as possible the average 90-10 wage premium for the U.S. economy over the $1963-1980$ period, a time when wage premium (3.2 by our measure) was noticeably lower than the benchmark period of 1992 (when the estimated premium is 4.1), while maintaining the benchmark value for the aggregate stock of human capital ( $H=1161.2)$. The resulting distribution of human capital (labelled "low-heterogeneity distribution") is displayed against the actual data and the benchmark distribution from the model (labelled "fitted") in Figure 2. As can be seen, the low-heterogeneity distribution is flatter than the original; it turns out that the two are also statistically distinguishable. Table 3 compares the resulting steady state (labelled "less heterogenous human capital") with the steady state under the benchmark specification.

With a more homogenous workforce, the benchmark allocation of human capital becomes inefficient. To restore equality in the wages paid per unit of human capital $\left(\tilde{w}^{\prime} s\right)$, a more symmetric allocation of labor is required. Thus labor is reallocated away from the oldest vintage and toward the latest vintage. As reported in Table 3, this reallocation is substantial, with labor allocated to the oldest vintage of capital falling sharply (i.e., by nearly 12 percent), while the allocation to the newest vintage rises substantially (i.e., by more than 13 percent); there is also a modest increase in the labor allocated to the second oldest vintage 
(which goes up by roughly 5 percent). This redeployment of the workforce that results from the flattening of the economy's human capital distribution is accompanied by a reduction in the wage premium. The highest hourly wage $\left(\tilde{v}^{1}\right)$ falls by nearly 12 percent while the lowest hourly wage $\left(\tilde{v}^{3}\right)$ rises by more than 13 percent.

Due to the constant returns to scale technology, with a unitary elasticity of substitution of human capital between production processes, the change in the degree of heterogeneity of the workforce has almost no effect on consumption, investment, or output. These results reflect the unrealistic assumption that the stock of human capital remains unchanged as the degree of heterogeneity of worker skills changes. Even so, it allows us to illustrate how labor supply effects can dramatically affect the wage premium, in contrast to the exercises reported in the previous section which suggested that technology-driven demand for high skilled workers is unlikely to be sufficiently strong to induce changes in the wage premium that are comparable to those observed in the U.S. economy in the 1980s and 1990s.

\section{Conclusions}

This paper examines ways in which heterogeneity in the skill levels of the workforce may matter for an economy that employs a variety of technologies in production, and where the mix of those technologies is constantly evolving. When the most highly skilled workers are matched with the latest technologies, a reallocation of workers is always underway that aims to improve macroeconomic performance. Our theoretical results suggest that when embodied technological progress accounts for an increasing share of long-run economic growth, the greater efficacy of the workforce that this reallocation affords induces a decline in the savings rate with little change in output and employment, thus permitting an increase in aggregate consumption without the sacrifice of leisure. In the short-run, permanent shocks to embodied technology 
PRODUCTIVITY SHOCKS IN A MODEL WITH VINTAGE CAPITAL AND HETEROGENEOUS LABO\& have a transitory component to them because it takes time to "absorb" the new technology across vintages. This transitory feature of the shocks induces dominant substitution effects that raise the savings rate, increase employment, and stimulate output that is characterized by a investment boom. In contrast, permanent shocks to TFP induce a strong wealth effect in the consumption-savings decision that lowers the savings rate. In this case, employment and output rise, but the decomposition of output is indicative of a consumption boom.

Labor reallocation also plays an important role in how the wage premium behaves after a technology shock. In the case of an embodied technology shock, it tends to limit both the duration and the magnitude of the increase in the wage premium that follows an embodied technology shock. Somewhat surprisingly, labor reallocation also means that the wage premium goes up following a disembodied technology shock, because the economy responds by moving labor away from the newest and towards the oldest vintage.

In any case, neither of these two effects appears to be strong enough to account for the increases in wage dispersion that have been observed in the U.S. economy during the 1980s and 1990s. Our conclusion is that one must look to the supply side of the labor market for answers to this puzzle. Efforts to understand how the growth of human capital in the economy has been accompanied by distributional effects (with respect to worker skills) would likely be a fruitful avenue of future research. 
Table 1: Benchmark Parameters and Steady-State Values

\begin{tabular}{|c|c|c|c|c|c|c|}
\hline Parameters & $\begin{array}{c}\text { Benchmark } \\
\text { Values }\end{array}$ & Variables & $\begin{array}{c}\text { Steady-State } \\
\text { Values }\end{array}$ & Variables & $\begin{array}{c}\text { Steady-State } \\
\text { Values }\end{array}$ \\
\hline$\alpha$ & 0.33 & $\tilde{c}$ & 840.81 & $z$ & 0.36 \\
$\delta$ & 0.9847 & $\tilde{i}$ & 520.37 & $\hat{x}^{1}$ & 0.26 \\
$\eta$ & $1 / 3$ & $\tilde{y}$ & 1361.18 & $\hat{x}^{2}$ & 0.31 \\
$\bar{\gamma}$ & 1.7437 & $\tilde{K}^{1}$ & 507.68 & $\hat{x}^{3}$ & 0.43 \\
$\bar{G}$ & 1.015 & $\tilde{K}^{2}$ & 338.45 & $N^{1}$ & 9.47 \\
$P$ & 1.025 & $\tilde{K}^{3}$ & 225.63 & $N^{2}$ & 11.11 \\
$T$ & 3 & $r^{1}$ & $6.080^{*}$ & $N^{3}$ & 15.42 \\
$S_{0}$ & 10.01 & $r^{2}$ & $4.906^{*}$ & $H^{1}$ & 642.35 \\
$\phi$ & 2.187 & $r^{3}$ & $3.768^{*}$ & $H^{2}$ & 405.35 \\
$\rho_{A}=\rho_{m}$ & 0.2 & $p^{1}$ & 0.970 & $H^{3}$ & 255.79 \\
$\sigma_{A}$ & 0.021 & $p^{2}$ & 0.941 & $\tilde{v}^{1}$ & 42.90 \\
$\sigma_{m}$ & 0.03 & $p^{3}$ & 0.913 & $\tilde{v}^{2}$ & 23.08 \\
\hline
\end{tabular}

$*$ in percent 
PRODUCTIVITY SHOCKS IN A MODEL WITH VINTAGE CAPITAL AND HETEROGENEOUS LABO\&

Table 2: Steady-State Effects of Changes in Embodied Technology's Share of Growth

\begin{tabular}{|c|c|c|}
\hline $\begin{array}{l}\text { variable/ } \\
\text { statistic }\end{array}$ & $\begin{array}{l}\text { benchmark } \\
\bar{\gamma}=1.015\end{array}$ & $\begin{array}{l}\text { All growth from embodied tech. } \\
\qquad \bar{\gamma}=1.025 \\
\text { percentage change }\end{array}$ \\
\hline normalized consumption, $\tilde{c}$ & 840.81 & 0.4 \\
\hline normalized investment, $\tilde{i}$ & 520.37 & -1.4 \\
\hline normalized output, $\tilde{y}$ & 1361.18 & -0.3 \\
\hline emp. share allocated to vintage $1, \hat{x}^{1}$ & 0.26 & 1.9 \\
\hline emp. share allocated to vintage $2, \hat{x}^{2}$ & 0.31 & 0.7 \\
\hline emp. share allocated to vintage $3, \hat{x}^{3}$ & 0.43 & -1.6 \\
\hline total hours worked, $N^{1}+N^{2}+N^{3}$ & 36.00 & 0.04 \\
\hline real net rental rate on $K^{1}, r^{1}$ & 6.08 & $1.3^{*}$ \\
\hline real net rental rate on $K^{2}, r^{2}$ & 4.90 & $0.5^{*}$ \\
\hline real net rental rate on $K^{3}, r^{3}$ & 3.77 & $-0.3^{*}$ \\
\hline normalized hourly wage: vintage $1, \tilde{v}^{1}$ & 42.90 & -0.1 \\
\hline normalized hourly wage: vintage $2, \tilde{v}^{2}$ & 23.08 & -0.9 \\
\hline normalized hourly wage: vintage $3, \tilde{v}^{3}$ & 10.49 & -0.5 \\
\hline savings rate, $\left(\frac{\tilde{i}}{\tilde{y}}\right)$ & 38.23 & -1.1 \\
\hline $\log$ of the wage premium, $\log \left(\frac{\tilde{v}^{1}}{\tilde{v}^{3}}\right)$ & 1.41 & $0.3^{* *}$ \\
\hline variance of log wages & 3.76 & 0.1 \\
\hline
\end{tabular}

* changes in the percent rates of return

** percentage change of the ratio $\left(\frac{\tilde{v}^{1}}{\tilde{v}^{3}}\right)$ 


\section{Table 3: Steady-State Effects of Changes in Labor Force} Heterogeneity

\begin{tabular}{|c|c|c|}
\hline $\begin{array}{l}\text { variable/ } \\
\text { statistic }\end{array}$ & benchmark & $\begin{array}{l}\text { low-heterogeneity case } \\
\text { (percentage change) }\end{array}$ \\
\hline labor hours allocated to vintage $1, N^{1}$ & 9.470 & 13.3 \\
\hline labor hours allocated to vintage $2, N^{2}$ & 11.11 & 5.1 \\
\hline labor hours allocated to vintage $2, N^{3}$ & 15.42 & -11.9 \\
\hline total stock of human capital, $H^{1}+H^{2}+H^{3}$ & 1303.49 & no change \\
\hline normalized hourly wage: vintage $1, \tilde{v}^{1}$ & 42.90 & -11.8 \\
\hline normalized hourly wage: vintage $2, \tilde{v}^{2}$ & 23.08 & -4.9 \\
\hline normalized hourly wage: vintage $3, \tilde{v}^{3}$ & 10.49 & 13.5 \\
\hline wage premium, $\left(\frac{\tilde{v}^{1}}{\tilde{v}^{3}}\right)$ & 4.09 & -22.2 \\
\hline log of the wage premium & 1.41 & -17.8 \\
\hline
\end{tabular}


PRODUCTIVITY SHOCKS IN A MODEL WITH VINTAGE CAPITAL AND HETEROGENEOUS LABOR

\section{References}

Abowd, John M., Paul A. Lengermann, and Kevin J. McKinney. (2002) "The Measurement of Human Capital in the U.S. Economy", U.S. Census Bureau LEHD Program Technical paper No. TP-2002-09.

Aghion, Phillipe. (2002) "Schumpeterian Growth Theory and the Dynamics of Income Inequality." Econometrica, May, pp. 855-882.

Autor, David, Lawrence Katz and Alan Krueger. (1998) "Computing Inequality: Have Computers Changed the Labor Market?" Quarterly Journal of Economics, November, pp. 1169-1214.

Benhabib, Jess and Bart Hobijn. (2001) Another View of Investment: 40 Years Later, in: J.Stiglitz, R.Frydman, M.Woodford, and P.Aghion (eds.), Knowledge, Information and Expectations in Modern Macroeconomics: In Honor of Edmund S. Phelps, 2003, 522- 545, Princeton University Press: Princeton

Card, David and John DiNardo. (2002) "Skill Biased Technological Change and Rising Inequality: Some Problems and Puzzles." Journal of Labor Economics, 20(4), pp. 733-783.

Christiano, Lawrence J.(2002) "Solving Dynamic Equilibrium Models by a Method of Undetermined Coefficients." Computational Economics 20(1-2) pp. 21-55

Gilchrist, Simon and John Williams. (2000) "Putty-Clay and Investment: A Business Cycle Analysis." Journal of Political Economy, volume 108, pages 928960 .

Gordon, Robert. (1990) The Measurement of Durable Goods Prices, Chicago: University of Chicago Press. 
Greenwood, Jeremy and Mehmet Yorukoglu. (1997)"1974", CarnegieRochester Conference Series on Public Policy, v. 46, pp. 49-95.

Greenwood, Jeremy, Zvi Hercowitz, and Per Krusell. (1997) "LongRun Implications of Investment-Specific Technological Change", American Economic Review, 87:3, pp. 342- 362.

Hornstein, Andreas and Per Krusell. (2002) "From factor-specific technical change to wage inequality and back again: A quantitative-theoretic study of the macroeconomic effects of IT", Federal Reserve Bank of Richmond Economic Quarterly, pp. 1-28.

Jovanovic, Boyan. (1998) "Vintage Capital and Inequality", Review of Economic Dynamics, vol. 1, pp. 497-530.

Katz, Lawrence and Kevin Murphy. (1992) "Changes in Relative Wages, 1963-1987: Supply and Demand Factors." Quarterly Journal of Economics, February, pp. 33-60.

Krusell, Per, Lee Ohanian, Jose-Victor Rios-Rull and Giovanni Violante. (2000) "Capital-Skill Complementarity and Inequality: A Macroeconomic Analysis", Econometrica, September, pp. 1029-1053.

Lucas, Robert E., Jr. (1980) "Equilibrium in a Pure Currency Economy," Economic Inquiry, vol 18(2), pp.203-220.

Phelps, Edmund S. (1962) "The New View of Investment: A Neoclassical Analysis", Quarterly Journal of Economics, 78(1), pp. 172-176.

Mehra, Rajnish, and Edward C. Prescott. (1985) "The equity premium: a puzzle," Journal of Monetary Economics, 15, pp. 145-161. 
PRODUCTIVITY SHOCKS IN A MODEL WITH VINTAGE CAPITAL AND HETEROGENEOUS LABOBR

Wilson, Dan. (2001) "Capital-Embodied Technical Change: Measurement and Productivity Effects." Ph.D. Dissertation, University of Maryland, May.

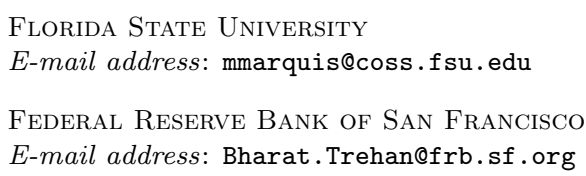



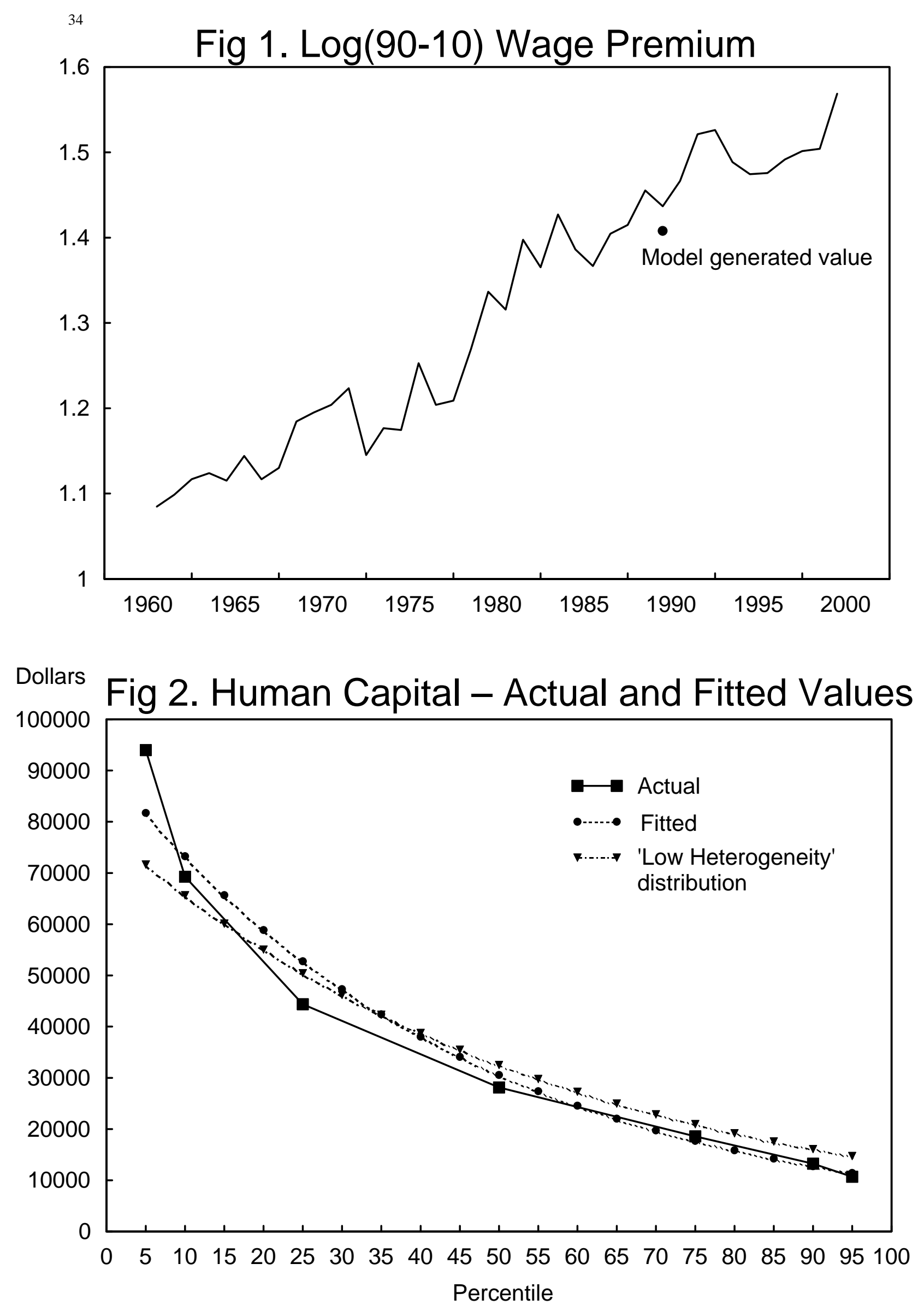
Fig 3. Responses to a Single Technology Shock - I

A. Savings Rate
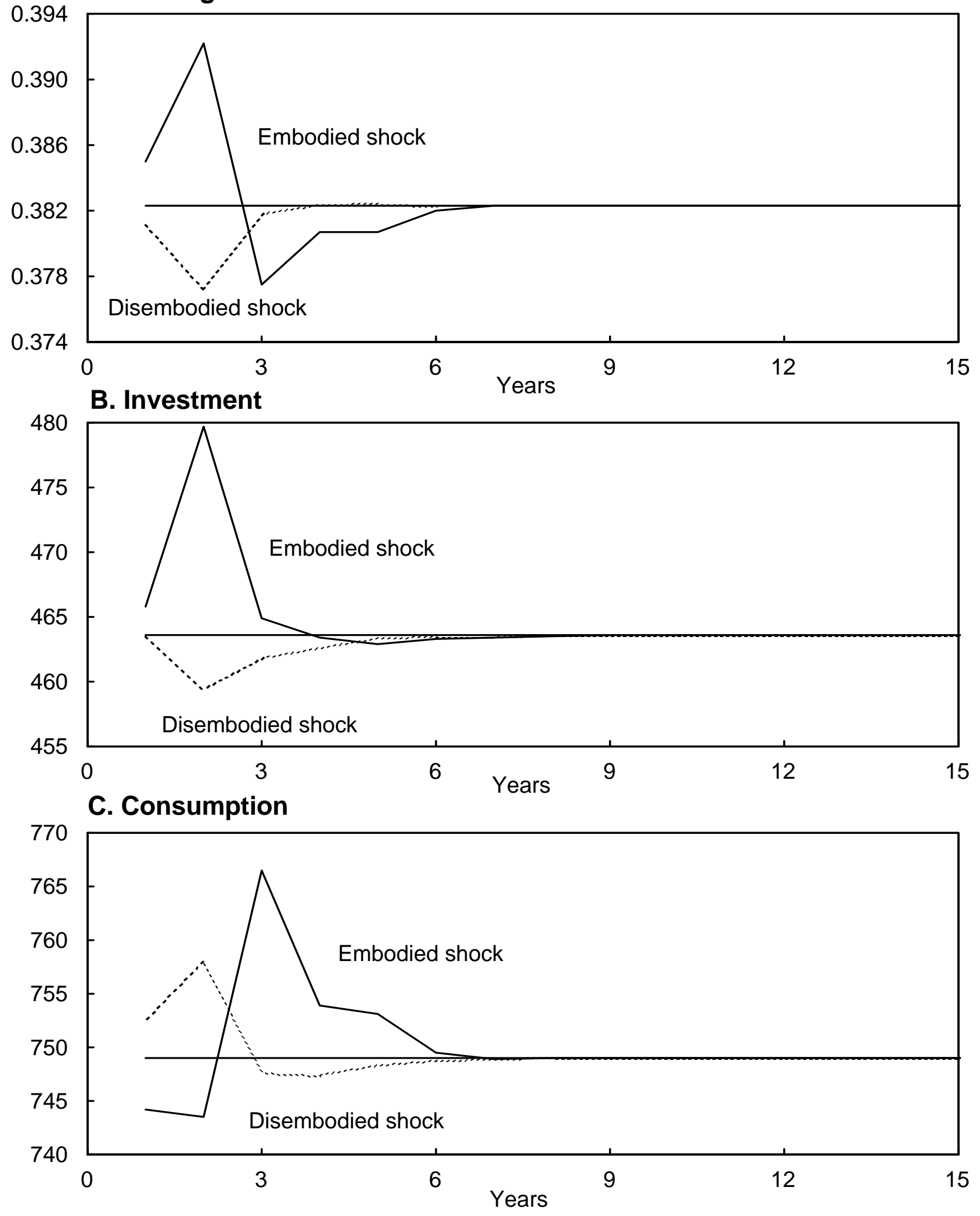
Fig 4. Responses to a Single Technology Shock - II

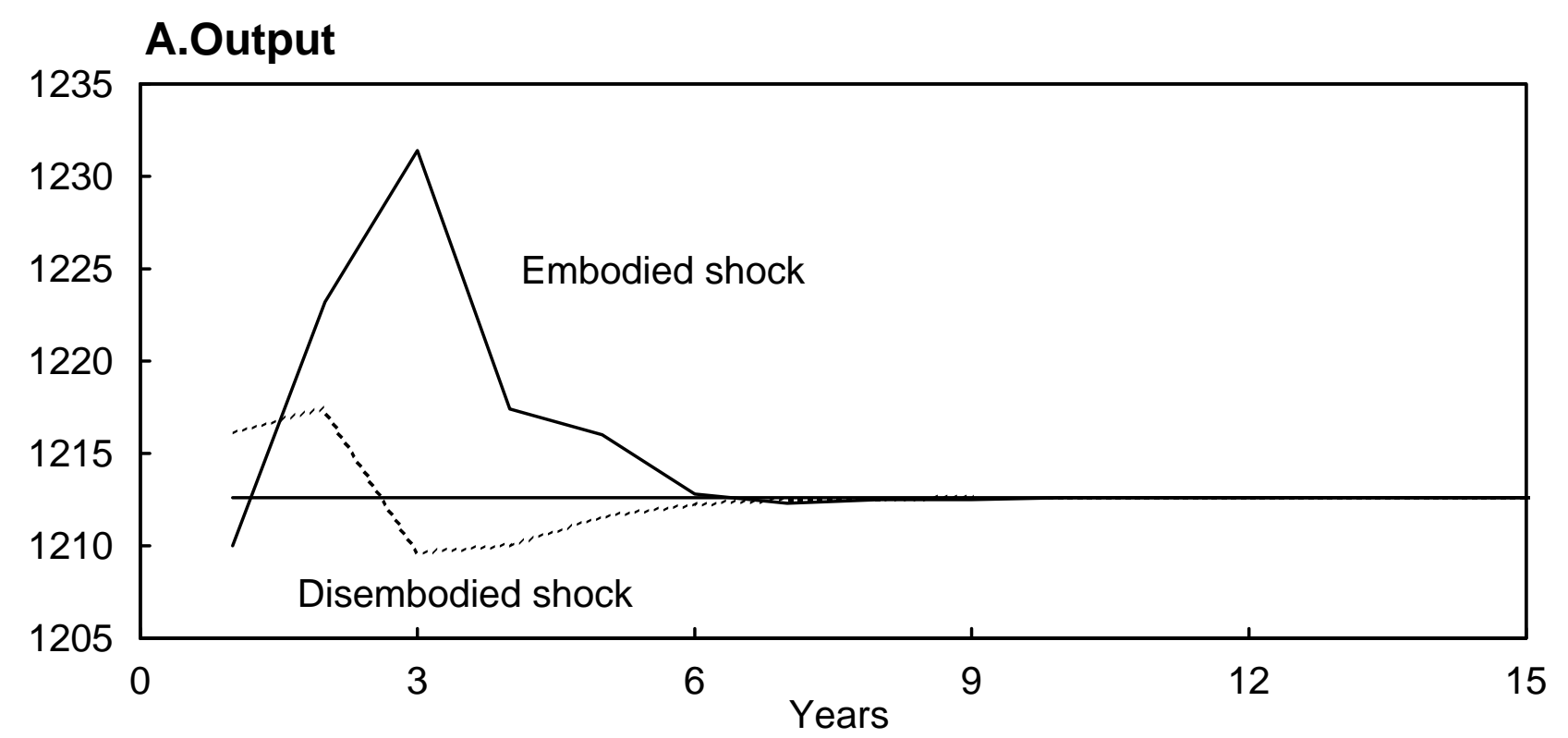

B. Labor Hours

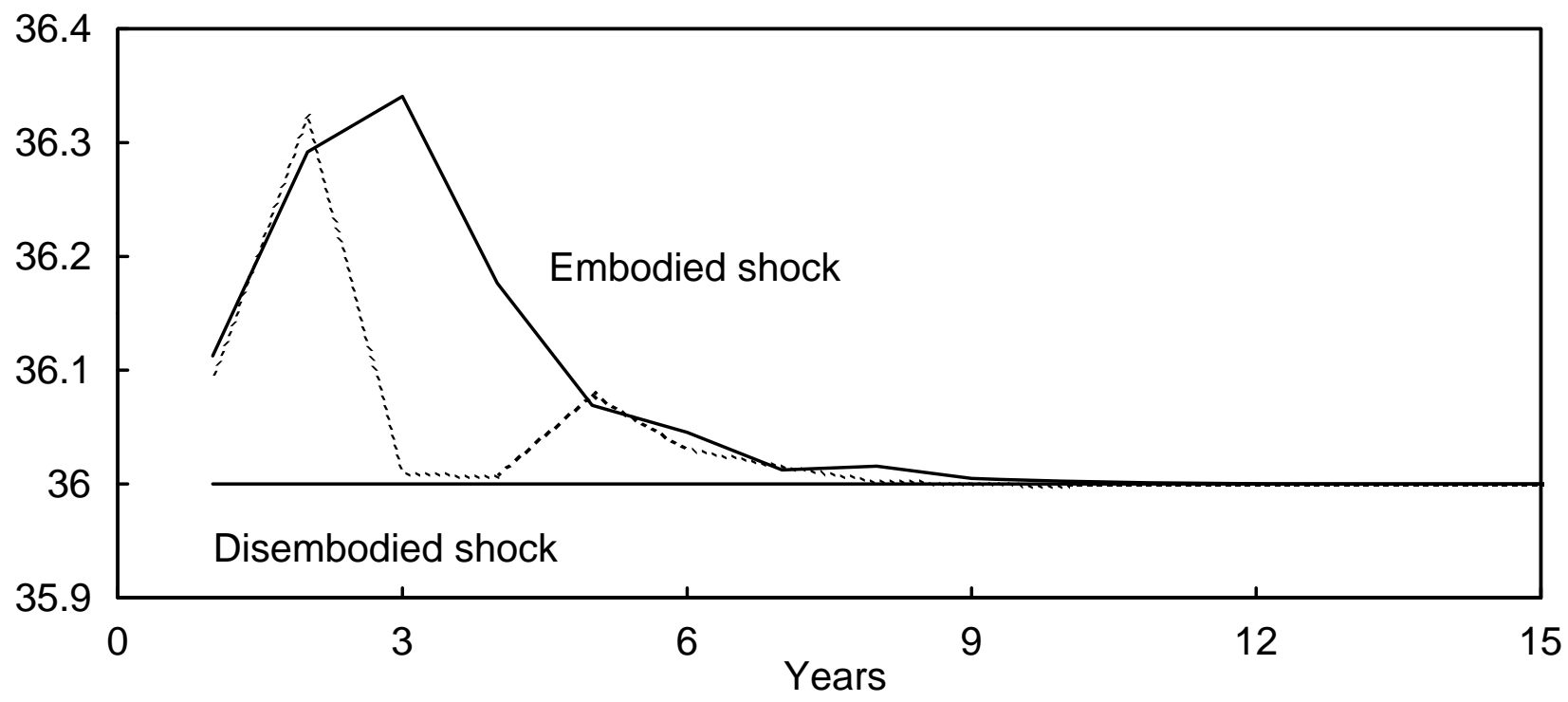




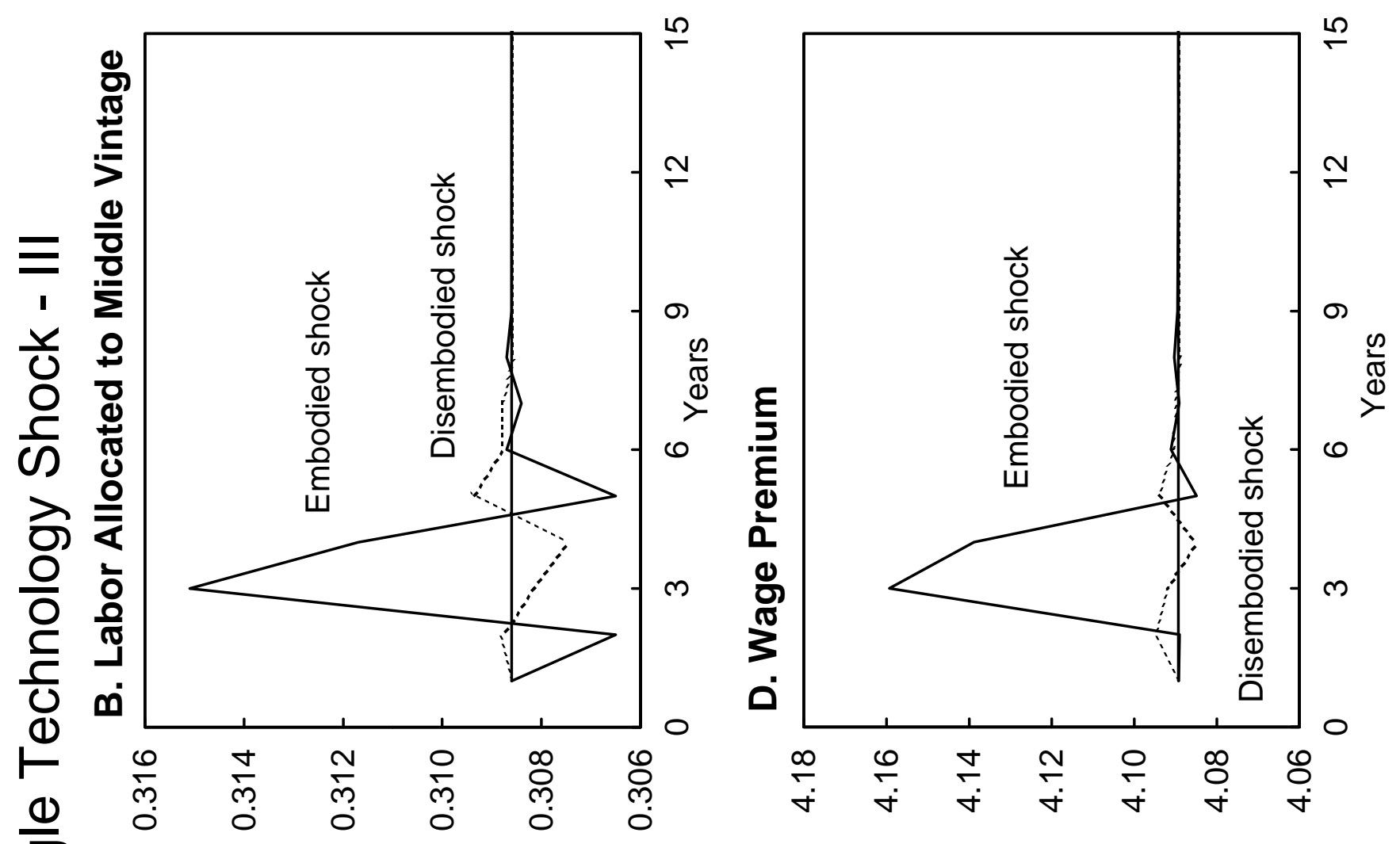

ত్ర
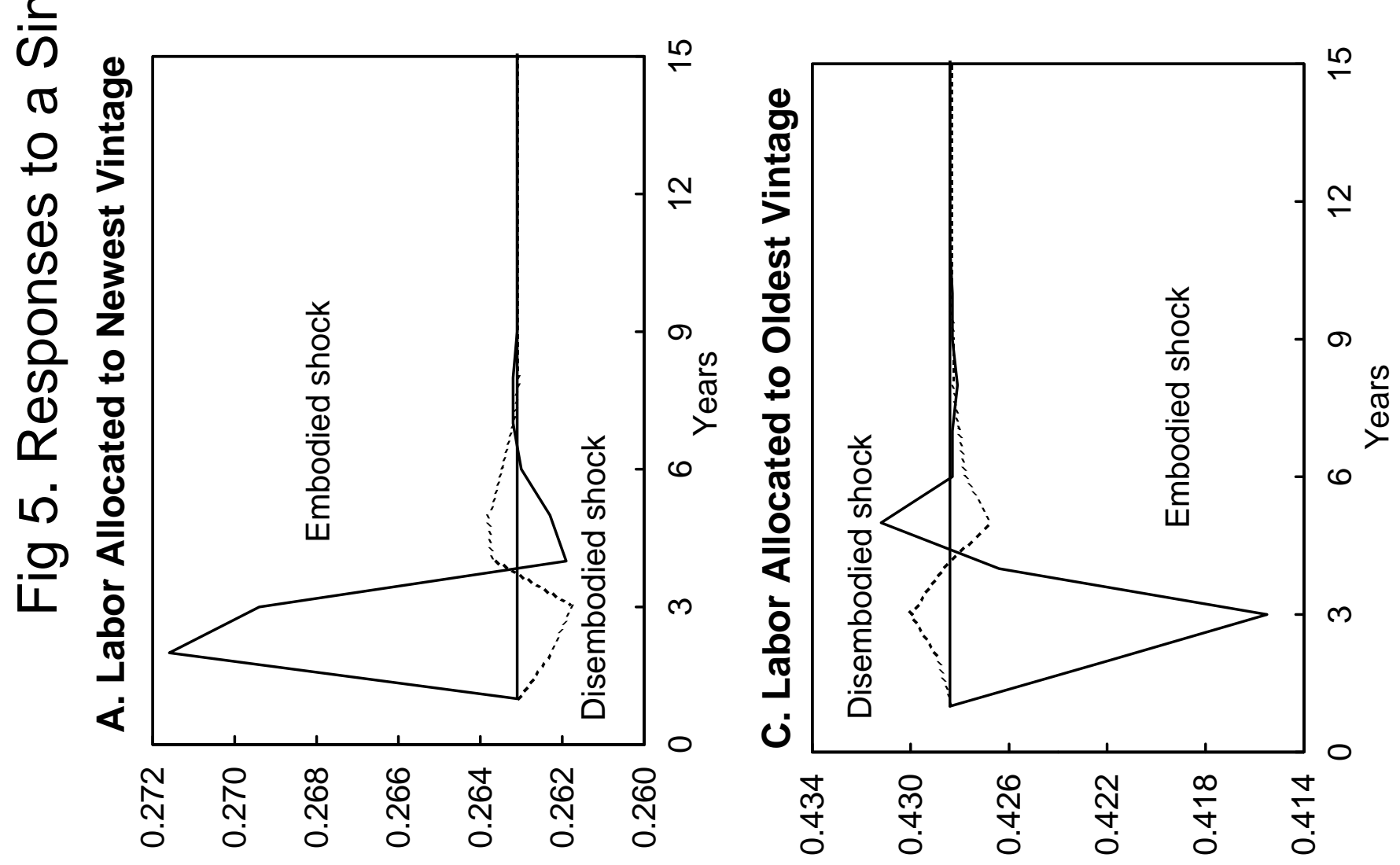

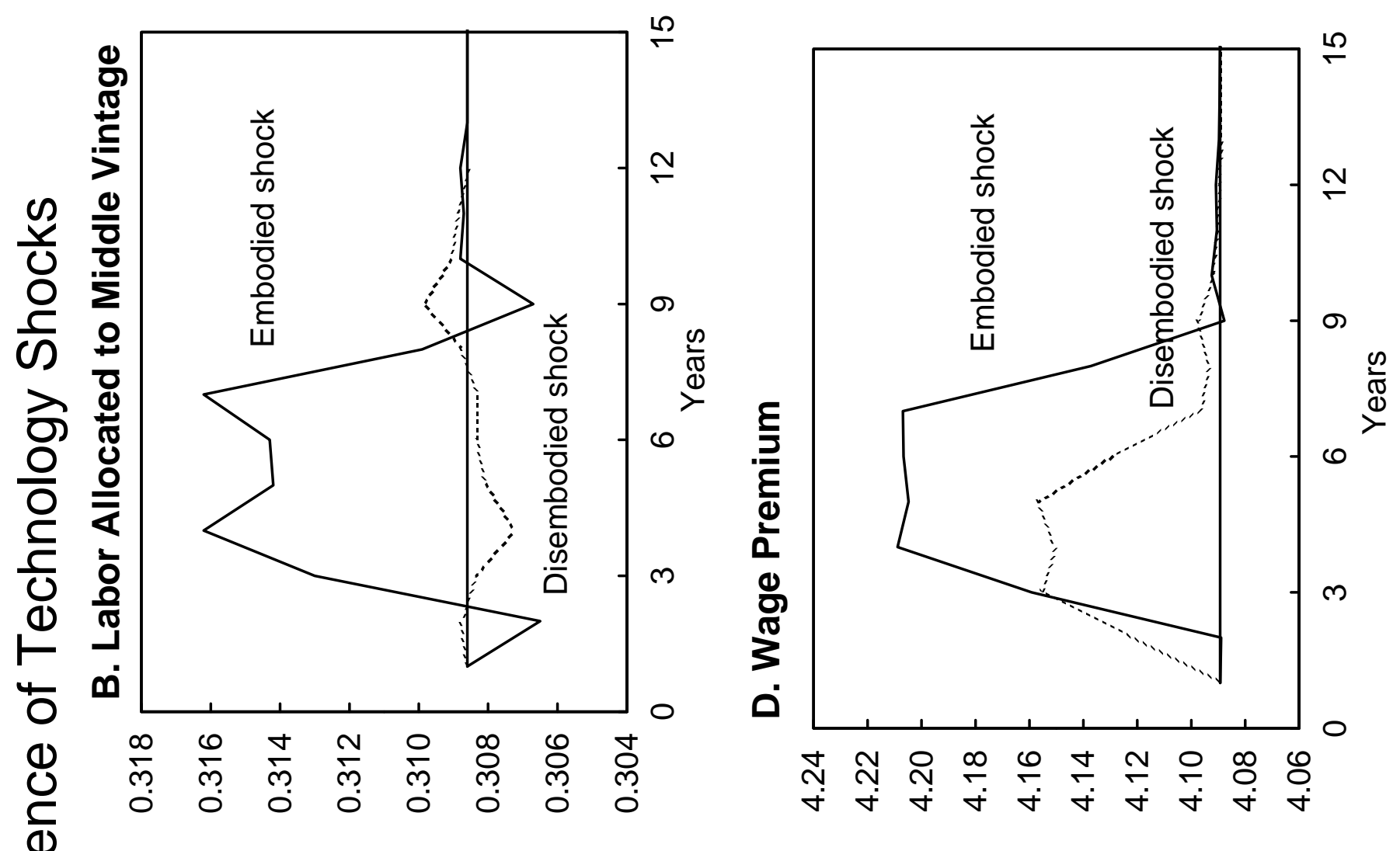

อิ
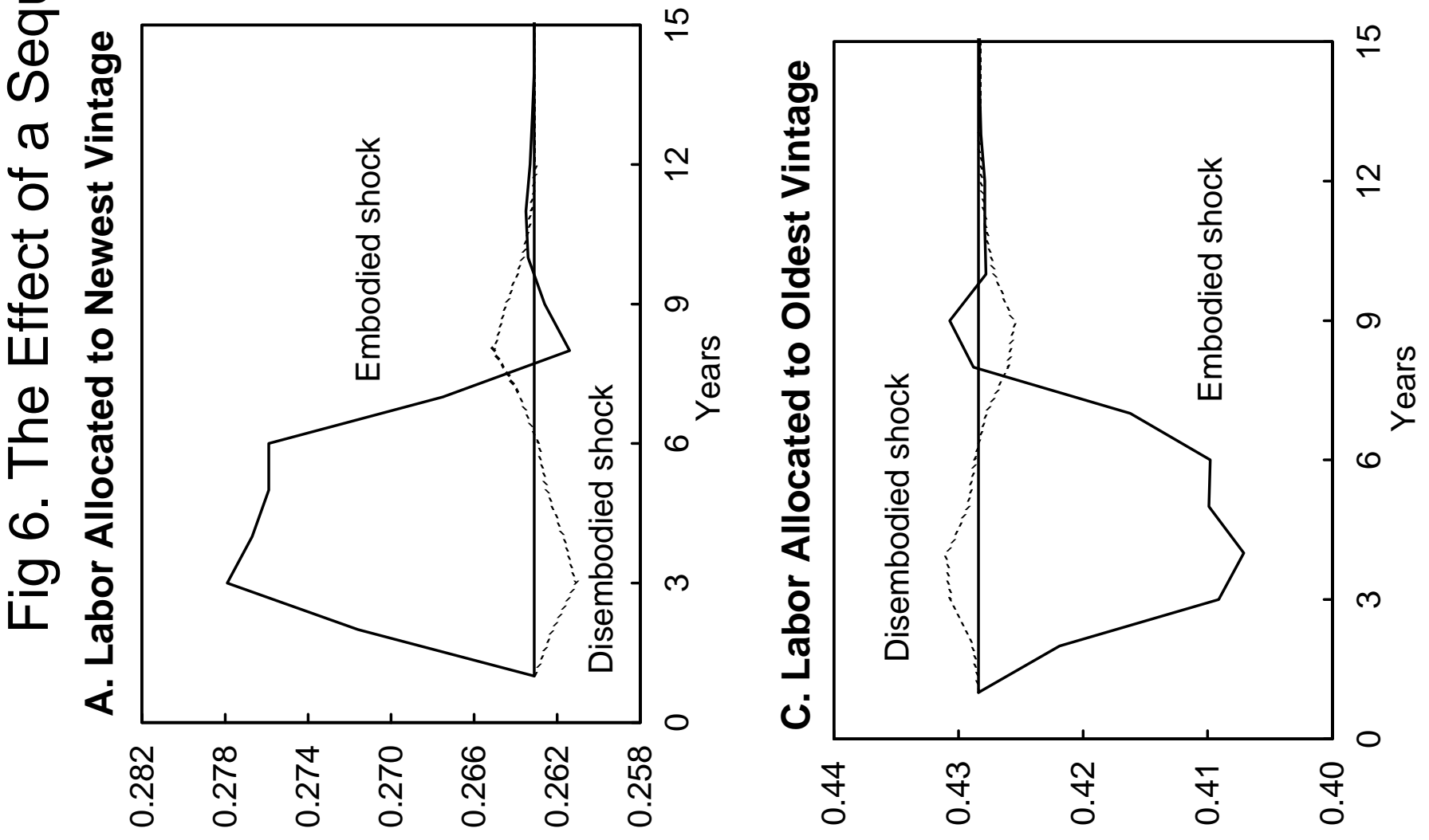